\title{
Catalyst-loaded Micro-encapsulated Phase Change Material for Thermal Control of Exothermic Reaction
}

\author{
Tatsuya Takahashi \\ Hokkaido University \\ Hiroaki Koide \\ Hokkaido University \\ Hiroki Sakai \\ Hokkaido University \\ Daisuke Ajito \\ Hokkaido University \\ Ade Kurniawan \\ Hokkaido University \\ Yuji Kunisada \\ Hokkaido University \\ Takahiro Nomura ( $\square$ nms-tropy@eng.hokudai.ac.jp ) \\ Hokkaido University
}

\section{Research Article}

Keywords: Thermal control, Phase change material, Microcapsule, CO2 methanation, Catalyst. CCUS (Carbon dioxide Capture, Utilization and Storage)

Posted Date: December 10th, 2020

DOI: https://doi.org/10.21203/rs.3.rs-122324/v1

License: (c) (1) This work is licensed under a Creative Commons Attribution 4.0 International License. Read Full License

Version of Record: A version of this preprint was published at Scientific Reports on April 6th, 2021. See the published version at https://doi.org/10.1038/s41598-021-86117-1. 
Title

\section{Catalyst-loaded micro-encapsulated phase change material}

\section{for thermal control of exothermic reaction}

Tatsuya Takahashi ${ }^{1}$, Hiroaki Koide ${ }^{1}$, Sakai Hiroki ${ }^{1}$, Daisuke Ajito ${ }^{1}$, Ade Kurniawan ${ }^{2}$, and Yuji Kunisada ${ }^{2}$, Takahiro Nomura ${ }^{2 *}$

${ }^{1}$ Graduate School of Engineering, Hokkaido University, Kita 13 Nishi 8, Kita-ku,

Sapporo, 060-8628 Japan

${ }^{2}$ Faculty of Engineering, Hokkaido University, Kita 13 Nishi 8, Kita-ku, Sapporo, 0608628 Japan

*Corresponding author.

Tel.: +8111706 6842; fax: +81117066849

E-mail address:nms-tropy@eng.hokudai.ac.jp (T.Nomura) 


\section{Abstract}

$\mathrm{CO}_{2}$ methanation is a promising technology to enable the use of $\mathrm{CO}_{2}$ as a resource.

Thermal control of $\mathrm{CO}_{2}$ methanation, which is a highly active exothermic reaction, is important to avoid thermal runaway and subsequent degradation of the catalyst. Using the heat storage capacity of a phase change material (PCM) for thermal control of the reaction is a novel passive approach. In this study a novel structure was developed, wherein catalysts were directly loaded onto a micro-encapsulated PCM (MEPCM). The MEPCM was prepared in three steps consisting of a boehmite treatment, precipitation treatment, and heat oxidation treatment, and an impregnation process was adopted to prepare a Ni catalyst. The catalyst-loaded MEPCM did not show any breakage or deformation of the capsule or a decrease in the heat storage capacity after the impregnation treatment. MEPCM demonstrated a higher potential as an alternative catalyst support in $\mathrm{CO}_{2}$ methanation than the commercially available $\alpha-\mathrm{Al}_{2} \mathrm{O}_{3}$ particle. In addition, the heat storage capacity of the catalyst-loaded MEPCM suppressed the temperature rise of the catalyst bed at a high heat absorption rate $\left(2.4 \mathrm{MW} \mathrm{m}^{-3}\right)$. In conclusion, the catalyst-loaded MEPCM is a high-speed, high-precision thermal control device because of its high-density energy storage and resolution of a spatial gap between the catalyst and cooling devices. This novel concept has the potential to overcome the 
technical challenges faced by efficiency enhancement of industrial chemical reactions.

\section{Keywords}

Thermal control; Phase change material; Microcapsule; $\mathrm{CO}_{2}$ methanation; Catalyst; CCUS (Carbon dioxide Capture, Utilization and Storage) 


\section{Introduction}

Thermal control is essential for operating various systems at appropriate temperatures and preventing system failures. Thermal runaway is one of the problems caused by an inability to properly control the reaction temperature. It is a positive loop state wherein the heat of an exothermic reaction causes the catalyst temperature to rise, which in turn promotes the reaction and further increases the catalyst temperature. This phenomenon occurs in chemical reactors and batteries and eventually results in the loss of control over

the system and possible explosion ${ }^{1-3}$. Thermal runaway in a heterogeneous catalytic reaction is also an economical problem because it reduces product selectivity, changes product distribution, and reduces the activity and life span of the catalyst ${ }^{2}$. Industrial fixed-bed reactors are operated at relatively high temperatures for the efficient conversion of reactants to products ${ }^{1}$. In this case, the temperature of the hot spot in the catalyst layer is close to the unstable range, and a slight disturbance in operating conditions can cause thermal runaway.

As one of the promising thermal control technologies, latent heat storage (LHS), which exploits the latent heat at the solid-liquid phase transformation of a phase change material (PCM), has attracted attention for its variety of positive characteristics, such as the release 
and absorption of a large amount of heat within a small temperature range, high repeatability, and heat transfer at a constant temperature ${ }^{4-7}$. Therefore, LHS behaves as an isothermal heat sink when the operation temperature matches the melting temperature of the PCM and precise temperature control within a narrow range is expected. Furthermore, passive thermal control, including LHS, is used more often than active thermal control owing to its higher operational reliability and lower $\operatorname{cost}^{8,9}$. However, the available temperature range of LHS depends mainly on the type of PCM used ${ }^{10,11}$. Typically, molten salts or alloys are used in the high temperature range that favors a chemical reaction ${ }^{4,12,13}$. Alloys are more promising than molten salts because of their high thermal conductivity, low volume expansion, and minimal supercooling ${ }^{12,13}$. Some alloy PCMs have been reported recently. Blanco-Rodríguez et al. reported a $\mathrm{Mg}-\mathrm{Zn}$ alloy, and Risueñoa et al. investigated $\mathrm{Mg}-\mathrm{Zn}-\mathrm{Al}$ alloys ${ }^{14,15}$. In several of these studies, the leakage of molten PCM is a problem, and encapsulation of the PCM is essential to prevent it $^{16}$.

Our research group previously developed a micro-encapsulated PCM (MEPCM) consisting of an Al-Si alloy core and an $\alpha-\mathrm{Al}_{2} \mathrm{O}_{3}$ shell ${ }^{17-19}$. The MEPCM exhibited a high melting point above $500{ }^{\circ} \mathrm{C}$, high heat storage density of $180 \mathrm{~J} \mathrm{~g}^{-1}$ or higher, and durability over 3000 cycles. Furthermore, microscale encapsulation provided beneficial properties for thermal control: miniaturization of the PCM enabled rapid melting of the internal 
alloy $^{2}$, and expansion of the heat exchange area provided rapid thermal response ${ }^{20}$.

Several thermal control technologies utilizing LHS have been reported. Zhang et al. used $\mathrm{In} @ \mathrm{SiO}_{2}$ capsules as a thermally functional additive to suppress the generation of local hot $\operatorname{spots}^{2}$. Ademola et al. investigated a simulation of the Fischer-Tropsch reaction using PCM, wherein the reaction bed temperature was maintained in the appropriate range ${ }^{1}$. LHS is also used to maintain the system temperature and to balance the heat demand and supply. Gokon et al. proposed a PCM-solar reactor to suppress the temperature change of a catalyst bed due to solar radiation fluctuation ${ }^{21}$; high catalyst performance was maintained for 30 min during the heat-discharging mode. Richard et al. proposed autothermal microchannel reactors in which the heat of the exothermic reaction was used in the endothermic reaction ${ }^{22}$. They confined the PCM layer between each reactor to suppress the thermal imbalance of the two reactions. On the other hand, when PCM is used as an additive in the catalyst layer or as a reactor jacket, the spatial gap between the heat source and PCM inhibits efficient heat conduction. Hence, the contact structure between the PCM surface and heat source is important for thermal $\operatorname{control}^{23}$. Li et al. demonstrated the heat management of a chemical loop combustion in contact with $\mathrm{Al} @ \mathrm{Al}_{2} \mathrm{O}_{3}$ PCM microcapsules ${ }^{23}$. However, there are few studies on thermal management components where a heat source was loaded onto the PCM 
capsule.

Therefore, a structure in which the catalyst acts as a heat source for the exothermic reaction when loaded onto the surface of an MEPCM is a novel and promising heat control material. Ceramic materials, such as $\mathrm{SiO}_{2}, \mathrm{Al}_{2} \mathrm{O}_{3}$, and $\mathrm{TiO}_{2}$, are often used as catalyst supports due to their high heat resistance and chemical stability ${ }^{24}$. Since the MEPCM shell consists of $\alpha-\mathrm{Al}_{2} \mathrm{O}_{3}$, it can be used as a catalyst support. Fig. 1 shows a schematic diagram of the catalyst-loaded MEPCM and the thermal control system. The MEPCM, which is covered with fine particles of the catalyst, removes the heat generated on the catalyst surface during exothermic reactions at the nanoscale because of its heat storage capacity. Catalyst-loaded MEPCMs are used in combination with typical cooling devices (e.g., shell and tube reactor ${ }^{25}$ ). These units cool the entire catalyst layer and prevent the PCM from losing its thermal storage characteristics due to a complete phase transformation. Thus, the catalyst-loaded MEPCM is expected to control the temperature of the entire catalyst layer at the nanoscale.

$\mathrm{CO}_{2}$ methanation $\left(\mathrm{CO}_{2}+4 \mathrm{H}_{2}=\mathrm{CH}_{4}+2 \mathrm{H}_{2} \mathrm{O}(\mathrm{g}), \Delta \mathrm{H}_{298 \mathrm{~K}}^{0}=-164 \mathrm{~kJ} \mathrm{~mol}^{-1}\right)$ is considered as an important application of the catalyst-loaded MEPCM because of its demand for high thermal control ${ }^{26}$. It presents an alternative to conventional natural gas production by converting $\mathrm{CO}_{2}$ to $\mathrm{CH}_{4}$, which is effective for reducing $\mathrm{CO}_{2}$ emissions ${ }^{27}$. Additionally, 
$\mathrm{CH}_{4}$ is superior to $\mathrm{H}_{2}$ in terms of capital expenditure as transportation of $\mathrm{CH}_{4}$ can be achieved by using existing natural gas pipelines ${ }^{27,28}$. Based on the above, a power-to-gas system employing $\mathrm{CO}_{2}$ methanation has been previously proposed ${ }^{25,29,30} \cdot \mathrm{CO}_{2}$ methanation requires catalysts $(\mathrm{Ni}, \mathrm{Rh}, \mathrm{Ru}$, etc.), and $\mathrm{Ni}$, which is the most widely used, shows high catalytic activity from 300 to $400{ }^{\circ} \mathrm{C}^{28,31}$. However, thermal runaway is a concern due to the highly exothermic reaction ${ }^{32-34}$. The use of a Ni-loaded MEPCM (Ni/MEPCM) instead of a conventional catalyst may suppress a significant rise in temperature.

The purpose of this study was to fabricate Ni/MEPCM and investigate its catalytic activity for $\mathrm{CO}_{2}$ methanation and its thermal control characteristics during an exothermic reaction. Ni/MEPCM was fabricated by the conventional impregnation method because the MEPCM surface was assumed to behave in a manner similar to that of the surface of $\alpha-\mathrm{Al}_{2} \mathrm{O}_{3}$ powder. $\mathrm{A} \mathrm{CO}_{2}$ methanation reaction was conducted to measure the catalytic performance. Based on the results, $\mathrm{CO}_{2}$ conversion (\%) and $\mathrm{CH}_{4}$ selectivity (\%) were estimated.

\section{Methods}

\section{1. Preparation of MEPCM}


MEPCM was prepared from Al-Si microspheres $(25$ mass\% $\%$ i; Diameter: $<38 \mu \mathrm{m}$, Purity: 99.0\%, Hikari Material Industry Co. Ltd.). The melting point of the composition is approximately $577^{\circ} \mathrm{C}$. The encapsulation of the microspheres was performed in three steps consisting of a boehmite treatment, precipitation treatment, and heat oxidation treatment, as proposed in a previous study ${ }^{19}$. First, $300 \mathrm{~mL}$ of distilled water containing 1.0 g of $\mathrm{Al}(\mathrm{OH})_{3}$ (Purity: 99.99\%, Kojundo Chemical Lab. Co., Ltd.) was boiled with a hot stirrer. After adjusting the solution to a $\mathrm{pH}$ of 8.0 by adding a $1 \mathrm{M}$ solution of $\mathrm{NH}_{3}$, $10 \mathrm{~g}$ of the Al-Si microspheres were added to the water. The mixture was continuously stirred for $3 \mathrm{~h}$ to form $\mathrm{AlOOH}$ shells on the surfaces of the microspheres by the hydration reaction. Second, the solutions were cooled to $75^{\circ} \mathrm{C}$ and maintained at this temperature for $16 \mathrm{~h}$. Subsequently, the precursor samples were filtered and dried at $105^{\circ} \mathrm{C}$ overnight. Finally, $10 \mathrm{~g}$ of the precursor samples were heated from room temperature to $1150{ }^{\circ} \mathrm{C}$ at a rate of $10^{\circ} \mathrm{C} \min ^{-1}$ and maintained there for $6 \mathrm{~h}$ under an $\mathrm{O}_{2}$ gas flow (Purity: 99.5\%, rate: $2.0 \mathrm{~L} \mathrm{~min}^{-1}$ ) to form the $\alpha-\mathrm{Al}_{2} \mathrm{O}_{3}$ shells.

\section{2. Preparation of $\mathrm{Ni} / \mathrm{MEPCM}$}

Ni loading onto the MEPCM was carried out by the impregnation method, here, the raw materials were adjusted so that the amount of nickel supported in the final product 
was $10 \%$. An aqueous solution containing $5.0 \mathrm{~mL}$ of distilled water and $0.50 \mathrm{~g}$ of $\mathrm{Ni}\left(\mathrm{NO}_{3}\right)_{2} \cdot 6 \mathrm{H}_{2} \mathrm{O}$ (Purity: $99.9 \%$, Kojundo Chemical Lab. Co., Ltd.) was added to $0.90 \mathrm{~g}$ of the as-prepared MEPCM. The mixture was crystallized at $70{ }^{\circ} \mathrm{C}$ by a rotary evaporator (Shibata Scientific Technology Ltd, SRE-M3). The impregnated sample was dried at $105{ }^{\circ} \mathrm{C}$ for $24 \mathrm{~h}$, then calcined at $500{ }^{\circ} \mathrm{C}$ for $4 \mathrm{~h}$ to prepare the Ni/MEPCM. Ni/ $\alpha-\mathrm{Al}_{2} \mathrm{O}_{3}$ was also prepared for comparison by adding $0.90 \mathrm{~g}$ of $\alpha-\mathrm{Al}_{2} \mathrm{O}_{3}$ (Diameter $<38 \mu$ m, Purity: 99.9\%, Showa Denko Co., Ltd.) into another aqueous solution of distilled water and $\mathrm{Ni}\left(\mathrm{NO}_{3}\right)_{2} \cdot 6 \mathrm{H}_{2} \mathrm{O}$, as before, and the mixture was crystallized at $70{ }^{\circ} \mathrm{C}$. The impregnated sample was then dried at $105{ }^{\circ} \mathrm{C}$ for $24 \mathrm{~h}$ and calcined at $500{ }^{\circ} \mathrm{C}$ for $4 \mathrm{~h}$ to prepare the $\mathrm{Ni} / \alpha-\mathrm{Al}_{2} \mathrm{O}_{3}$ reference.

\section{3. Sample characterization}

The phase compositions of the samples were characterized using X-ray powder diffraction (XRD, Rigaku, Miniflex600, $\mathrm{Cu} \mathrm{K \alpha}$ ). The morphology was observed by scanning electron microscopy-energy dispersive spectroscopy (SEM-EDS, JEOL, JSM7400F). Brunauer-Emmett-Teller (BET) specific surface areas of the samples were analyzed based on the $\mathrm{N}_{2}$ adsorption/desorption techniques using a gas adsorption analyzer (Yuasa Ionics, Autosorb 6AG). The density of the samples was measured using 
a gas pycnometer (Quantachrome instruments, Ultrapycnometer1000). Additionally, the phase transition temperature and thermal storage ability were measured using a differential scanning calorimetry analyzer (DSC, Mettler-Toledo, TGA/DSC3+). The MEPCM sample was placed in an $\mathrm{Al}_{2} \mathrm{O}_{3}$ crucible and heated from room temperature to $600{ }^{\circ} \mathrm{C}$ at a rate of $2.0^{\circ} \mathrm{C} \min ^{-1}$ and maintained at this temperature for 5 min under an $\mathrm{Ar}$ gas flow (Purity $99.5 \%$, rate $50 \mathrm{~mL} \mathrm{~min}^{-1}$ ).

\section{4. $\mathrm{CO}_{2}$ methanation}

$\mathrm{CO}_{2}$ methanation was performed in a vertical fixed bed tubular reactor (inner diameter:

$6.0 \mathrm{~mm}$ ) at atmospheric pressure to evaluate the catalytic activity tests. Fig. 2 shows a schematic diagram of the reactor. One-tenth of a gram of the samples were loaded into the reactor and fixed with quartz wool. The samples were reduced for $1 \mathrm{~h}$ at $500{ }^{\circ} \mathrm{C}$ under $\mathrm{H}_{2}$ and $\mathrm{Ar}$ gas flow $\left(\mathrm{F}_{\mathrm{in}, \mathrm{H}_{2}}=40 \mathrm{~mL} \mathrm{~min}^{-1}\right.$ and $\mathrm{F}_{\mathrm{in}, \mathrm{Ar}}=100 \mathrm{~mL} \mathrm{~min}^{-1}$, where $\mathrm{F}_{\text {in, } x}$ represents the flow rate of the inlet gas). After cooling to the reaction temperature in $\mathrm{Ar}$ gas flow, the feed gas $\left(\mathrm{F}_{\mathrm{in}, \mathrm{CO}_{2}}=10 \mathrm{~mL} \min ^{-1}, \mathrm{~F}_{\mathrm{in}, \mathrm{H}_{2}}=40 \mathrm{~mL} \mathrm{~min}^{-1}\right.$, and $\mathrm{F}_{\mathrm{in}, \mathrm{Ar}}=110$ $\mathrm{mL} \mathrm{min}^{-1}$ ) was introduced into the reactor for $1 \mathrm{~h}$ at $400{ }^{\circ} \mathrm{C}$. The concentrations of the outlet gas was analyzed using a Quadrupole mass spectrometer (QMS, Pfeiffer Vacuum, Thermostar GSD301). $\mathrm{CO}_{2}$ conversion and $\mathrm{CH}_{4}$ selectivity were calculated using Eq. (1) 
and (2):

$$
\begin{aligned}
& \mathrm{CO}_{2} \text { conversion }(\%)=\frac{\left(\mathrm{F}_{\mathrm{in}, \mathrm{CO}_{2}}-\mathrm{F}_{\mathrm{out}, \mathrm{CO}_{2}}\right) \times 100}{\mathrm{~F}_{\mathrm{in}, \mathrm{CO}_{2}}} \\
& \mathrm{CH}_{4} \text { selectivity }(\%)=\frac{\mathrm{F}_{\text {out }, \mathrm{CH}_{4}} \times 100}{\left(\mathrm{~F}_{\text {out }, \mathrm{CH}_{4}}+\mathrm{F}_{\text {out }, \mathrm{CO}}\right)} \text {, }
\end{aligned}
$$

where $\mathrm{F}_{\text {out, } x}$ represents the flow rate of the outlet gas.

\section{5. Measurement of thermal control performance}

The $\mathrm{CO}_{2}$ methanation reaction was also used as a test to evaluate the thermal control characteristics of the Ni/MEPCM material. The reactions were carried out with Ni/MEPCM under two reaction conditions, and the temperature of the sample bed was measured in each case. The difference between the two conditions determined whether the internal PCM was a solid or liquid (i.e., whether the samples had a heat storage capacity or not). The temperature control performance of the PCM was evaluated from the difference between these temperatures.

The reaction was carried out in the same reactor as in section 2.4., and the thermocouple was inserted into the middle of the sample bed to measure the temperature of the sample. Two-tenths of a gram of the PCM samples were loaded into the reactor such that the tip of the thermocouple was sufficiently covered by the samples. Fig. 3 shows the two different reaction conditions. In condition A, when the temperature of the sample layer exceeded the melting point of the PCM by the reaction heat, the phase transformation of 
PCM occurred, and heat storage began. In condition B, the PCM melted before the reaction started, and the liquid state was maintained even at the reaction temperature for supercooling. Therefore, heat storage did not occur during the reaction. $\mathrm{H}_{2}$ and $\mathrm{Ar}$ gas $\left(\mathrm{F}_{\mathrm{in}, \mathrm{H}_{2}}=40 \mathrm{~mL} \mathrm{~min}^{-1}\right.$ and $\left.\mathrm{F}_{\mathrm{in}, \mathrm{Ar}}=100 \mathrm{~mL} \mathrm{~min}^{-1}\right)$ flowed during the reduction, and the

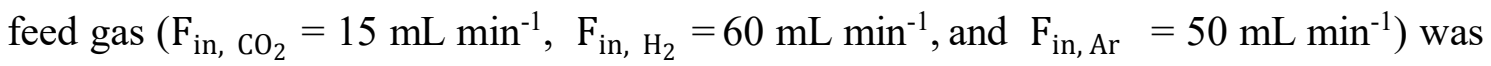
introduced during the reaction.

\section{Results and Discussion}

\section{1. Catalyst characterization}

\section{1. 1. Phase composition of samples}

Fig. 4 shows the XRD patterns of the MEPCM, Ni/MEPCM, and $\mathrm{Ni} / \alpha-\mathrm{Al}_{2} \mathrm{O}_{3}$ samples. Peaks of Al, $\alpha-\mathrm{Al}_{2} \mathrm{O}_{3}$, and Si were detected in the results of the MEPCM and Ni/MEPCM, and peaks of $\mathrm{NiO}$ was observed in the Ni/MEPCM. Peaks corresponding to $\alpha-\mathrm{Al}_{2} \mathrm{O}_{3}$ and $\mathrm{NiO}$ were detected in the $\mathrm{Ni} / \alpha-\mathrm{Al}_{2} \mathrm{O}_{3}$.

The XRD peaks of $\mathrm{Al}$ and $\mathrm{Si}$ were attributed to the core alloy in the MEPCM; meanwhile, the $\alpha-\mathrm{Al}_{2} \mathrm{O}_{3}$ peak was attributed to its shell. Stronger peaks of $\alpha-\mathrm{Al}_{2} \mathrm{O}_{3}$ were observed in the $\mathrm{Ni} / \alpha-\mathrm{Al}_{2} \mathrm{O}_{3}$ than in the other samples. This is due to the fact that only the shell of the MEPCM was composed of $\alpha-\mathrm{Al}_{2} \mathrm{O}_{3}$ as opposed to the entire structure of $\mathrm{Ni} / \alpha$ - 
$\mathrm{Al}_{2} \mathrm{O}_{3}$. Since the peaks of $\mathrm{NiO}$ and $\alpha-\mathrm{Al}_{2} \mathrm{O}_{3}$ were similar in all samples, the prepared samples were expected to have similar catalytic properties.

\section{1. 2. Morphology of samples}

Fig. 5 shows the SEM images and elemental mapping results of the MEPCM, $\mathrm{Ni} / \mathrm{MEPCM}$, and $\mathrm{Ni} / \alpha-\mathrm{Al}_{2} \mathrm{O}_{3}$ samples. The entire surface of the MEPCM was covered with a needle-like structure, and cuboid crystals had formed on the structure. The same structure along with fine particles of approximately $40 \mathrm{~nm}$ in diameter were present in the Ni/MEPCM. A smooth surface was detected in the $\mathrm{Ni} / \alpha-\mathrm{Al}_{2} \mathrm{O}_{3}$, and fine particles of approximately $100 \mathrm{~nm}$ in diameter were present on its surface. In the elemental mapping, the MEPCM shell was composed of Al, O, and a small amount of $\mathrm{Si}$, while Ni was present on the MEPCM shell after Ni impregnation in the Ni/MEPCM. In contrast, $\mathrm{Al}, \mathrm{O}$, and $\mathrm{Ni}$ were strongly detected in the $\mathrm{Ni} / \alpha-\mathrm{Al}_{2} \mathrm{O}_{3}$.

The needle-like structure and cuboid crystals were composed of Al and O, and the XRD patterns reveal $\alpha-\mathrm{Al}_{2} \mathrm{O}_{3}$ peaks. Thus, the MEPCM shells had formed only from $\alpha-\mathrm{Al}_{2} \mathrm{O}_{3}$. The characteristic needle-like structures corresponded to $\mathrm{AlOOH}$ formed during the boehmite treatment ${ }^{17}$. The cuboid crystals represented the deposited or adhered $\mathrm{Al}(\mathrm{OH})_{3}$ particles formed during the precipitation treatment ${ }^{19}$. These two types of structures 
created a coarse configuration. The small amount of Si that was detected implied that most of the Si was present only in the MEPCM core. The fine particles were present only in the Ni-impregnated sample; thus, they were considered to be $\mathrm{NiO}$ from the elemental mapping and XRD patterns. Ni was supported on the MEPCM without aggregation since these particles were distributed. As the core/shell structure was neither broken nor deformed, and there was no elemental mapping of Si outside the capsules, no apparent core leakage occurred during the impregnation process. On the other hand, in $\mathrm{Ni} / \alpha-\mathrm{Al}_{2} \mathrm{O}_{3}$, the particles recognized as $\mathrm{NiO}$ were more aggregated than those in the Ni/MEPCM, and Si was determined as a trace impurity in the production.

\section{1. 3. BET specific surface area of samples}

Table 1 shows the BET specific surface areas and densities of the MEPCM, $\mathrm{Ni} / \mathrm{MEPCM}$, and $\mathrm{Ni} / \alpha-\mathrm{Al}_{2} \mathrm{O}_{3}$. A difference in the interior composition of the $\mathrm{Ni} / \mathrm{MEPCM}$ and $\mathrm{Ni} / \alpha-\mathrm{Al}_{2} \mathrm{O}_{3}$ caused a difference in mass even at equal volumes. Therefore, these samples should be evaluated by the BET specific surface area per volume, which was converted from the specific surface area per mass using the density of each sample. The $\mathrm{Ni} / \mathrm{MEPCM}$ had the largest BET specific surface area at $38.2 \times 10^{6} \mathrm{~m}^{2} \mathrm{~m}^{-3}$. 
Table 1 BET specific surface areas per mass or volume, and densities of the MEPCM, $\mathrm{Ni} / \mathrm{MEPCM}$, and $\mathrm{Ni} / \boldsymbol{\alpha}-\mathrm{Al}_{2} \mathrm{O}_{3}$.

\begin{tabular}{|l|l|l|l|}
\hline & MEPCM & Ni/MEPCM & $\mathrm{Ni} / \alpha-\mathrm{Al}_{2} \mathrm{O}_{3}$ \\
\hline BET surface area $\left(\mathrm{m}^{2} \mathrm{~g}^{-1}\right)$ & 10.19 & 11.28 & 2.75 \\
\hline Density $\left(\mathrm{g} \mathrm{m}^{-3}\right)$ & $2.69 \times 10^{6}$ & $3.39 \times 10^{6}$ & $4.11 \times 10^{6}$ \\
\hline BET surface area $\left(\mathrm{m}^{2} \mathrm{~m}^{-3}\right)$ & $27.4 \times 10^{6}$ & $38.2 \times 10^{6}$ & $11.3 \times 10^{6}$ \\
\hline
\end{tabular}

The Ni/MEPCM showed a slightly larger surface area than that of the pure MEPCM since the crystals were formed on the surface of the MEPCM. At $11.3 \times 10^{6} \mathrm{~m}^{2} \mathrm{~m}^{-3}$, the surface area of the $\mathrm{Ni} / \alpha-\mathrm{Al}_{2} \mathrm{O}_{3}$ was smaller than that of the MEPCM owing to the 
smoother surface morphology of the $\alpha-\mathrm{Al}_{2} \mathrm{O}_{3}$ particles. Generally, $\alpha-\mathrm{Al}_{2} \mathrm{O}_{3}$ has a small specific surface area due to the formation process of $\alpha-\mathrm{Al}_{2} \mathrm{O}_{3}$, whereby the hightemperature heat treatment facilitates the rearrangement of the $\mathrm{Al}_{2} \mathrm{O}_{3}$ particles and reduces the surface $\operatorname{area}^{35}$. In contrast, the MEPCM had a higher specific surface area than that of ordinary $\alpha-\mathrm{Al}_{2} \mathrm{O}_{3}$ powder because of its rough structure. Therefore, MEPCM is superior to $\alpha-\mathrm{Al}_{2} \mathrm{O}_{3}$ powder as a catalyst support in terms of active-catalyst dispersion.

\section{2. Thermal properties}

Fig. 6 shows the DSC curves during heating of the MEPCM, Ni/MEPCM, and Ni/ $\alpha-$ $\mathrm{Al}_{2} \mathrm{O}_{3}$ samples. An endothermic peak at approximately $573{ }^{\circ} \mathrm{C}$ is near the eutectic temperature of Al-Si alloy in both the MEPCM and Ni/MEPCM. Also, the LHS capacities of the MEPCM and Ni/MEPCM were different at 191.42 and $177.84 \mathrm{~J} \mathrm{~g}^{-1}$, respectively. No endothermic peak was observed in the $\mathrm{Ni} / \alpha-\mathrm{Al}_{2} \mathrm{O}_{3}$.

Since the onset temperature of the endothermic peak was close to the eutectic temperature $\left(577{ }^{\circ} \mathrm{C}\right)$ of the Al-Si alloy, the endothermic peak arose from the phase change of the core alloy. Because Ni impregnated on the MEPCM as NiO particles (at 10 mass\% Ni), the LHS capacity of the Ni/MEPCM was $202.47 \mathrm{~J} \mathrm{~g}^{-1}$ if $\mathrm{NiO}$ was neglected. This value was not less than that of the MEPCM before Ni impregnation. Therefore, Ni 
does not affect the heat storage capacity of the MEPCM.

\section{3. $\mathrm{CO}_{2}$ methanation}

The catalytic activity of each sample was evaluated by analyzing the outlet gas with a quadrupole mass spectrometer during $\mathrm{CO}_{2}$ methanation. Fig. 7 shows the $\mathrm{CO}_{2}$ conversion of each catalyst. The average $\mathrm{CO}_{2}$ conversions of the $\mathrm{Ni} / \mathrm{MEPCM}$ and $\mathrm{Ni} / \alpha-\mathrm{Al}_{2} \mathrm{O}_{3}$ were $50 \%$ and $25 \%$, respectively. In contrast, the value of the pure MEPCM was nearly $7 \%$.

Since the pure MEPCM showed little catalytic activity, it was demonstrated that the Ni particles on the MEPCM drive catalytic activity. Moreover, the $\mathrm{CO}_{2}$ conversion of the $\mathrm{Ni} / \mathrm{MEPCM}$ exceeded that of the $\mathrm{Ni} / \alpha-\mathrm{Al}_{2} \mathrm{O}_{3}$ by approximately $25 \%$, suggesting that the MEPCM shell functions as a better catalyst support than ordinary $\alpha-\mathrm{Al}_{2} \mathrm{O}_{3}$. This is attributed to the increase in the specific surface area of the MEPCM compared to that of the $\mathrm{Ni} / \alpha-\mathrm{Al}_{2} \mathrm{O}_{3}$. Whereas the $\mathrm{Ni}$ loaded onto each sample showed the ability to promote $\mathrm{CO}_{2}$ hydration, catalytic performances of $\mathrm{Ni} / \mathrm{MEPCM}$ and $\mathrm{Ni} / \alpha-\mathrm{Al}_{2} \mathrm{O}_{3}$ were poor because the theoretical equilibrium of $\mathrm{CO}_{2}$ conversion was $97.50 \%$, assuming only $\mathrm{CH}_{4}$ and $\mathrm{CO}$ were generated at $400{ }^{\circ} \mathrm{C}^{36}$.

Fig. 8 shows the $\mathrm{CH}_{4}$ selectivity of each catalyst. The average $\mathrm{CH}_{4}$ selectivity of the $\mathrm{Ni} / \mathrm{MEPCM}$ and $\mathrm{Ni} / \alpha-\mathrm{Al}_{2} \mathrm{O}_{3}$ were $62 \%$ and $40 \%$, respectively. Meanwhile, the value of 
the pure MEPCM could not be calculated because of the small amount of generated byproduct. Since the Ni/MEPCM possessed a higher $\mathrm{CH}_{4}$ selectivity than $\mathrm{Ni} / \alpha-\mathrm{Al}_{2} \mathrm{O}_{3}$, it is clear that the MEPCM can replace the $\alpha-\mathrm{Al}_{2} \mathrm{O}_{3}$ support. The increase in the number of reaction sites was suspected as a factor for improving the $\mathrm{CH}_{4}$ selectivity. This could be inferred from the following three points: (1) the $\mathrm{CO}_{2}$ conversion of the Ni/MEPCM exceeded that of the $\mathrm{Ni} / \alpha-\mathrm{Al}_{2} \mathrm{O}_{3}$; (2) the surface area of the $\mathrm{Ni} / \mathrm{MEPCM}$ was larger than that of the $\mathrm{Ni} / \alpha-\mathrm{Al}_{2} \mathrm{O}_{3}$; (3) SEM images showed aggregation of the $\mathrm{NiO}$ particles on the $\alpha-\mathrm{Al}_{2} \mathrm{O}_{3}$.

$\mathrm{CO}_{2}$ methanation on Ni generally passes through $\mathrm{CO}$ as an intermediate ${ }^{37-39}$; therefore, a certain extent of $\mathrm{CO}$ production may be caused by incomplete reactions. It is assumed that the $\mathrm{CO}$ generation decreased due to the completion of the reaction as a result of the increase in the number of reaction sites. In the future, a detailed investigation of the surface properties of the Ni/MEPCM is needed to support this discussion. Additionally, both $\mathrm{CH}_{4}$ selectivities were lower than the theoretical equilibrium value, which is $99.87 \%$, assuming only $\mathrm{CH}_{4}$ and $\mathrm{CO}$ were generated at $400{ }^{\circ} \mathrm{C}^{36}$.

\section{4. Thermal control performance}

Fig. 9 shows the temperature change of the sample layer when $\mathrm{CO}_{2}$ methanation was 
performed under two conditions: with and without a heat storage capacity. These curves illustrate the average of five measurements, where feed gas was introduced 1 min after the measurement commenced. In both conditions, the temperature rose immediately after the injection of the feed gas. Without a heat storage capacity, the temperature of the sample layer increased linearly and stabilized at approximately $583{ }^{\circ} \mathrm{C}$. When the sample had a heat storage capacity, the rising temperature trend behaved differently. The temperature of the sample layer rose linearly to approximately $573{ }^{\circ} \mathrm{C}$, then gradually increased, stabilizing at approximately $583{ }^{\circ} \mathrm{C}$. Each experiment showed the same reaction rates.

We considered that the final temperature stabilization was caused by the balance between the generated reaction heat and the heat lost to the outside of the reactor. A gradual temperature rise was observed only in the samples with a heat storage capacity. In addition, the gradual temperature rise started around $573{ }^{\circ} \mathrm{C}$, which is close to eutectic temperature of the Al-Si alloy and the peak temperature of the phase transformation confirmed by DSC. Thus, we determined that the rate of increase of the temperature of the sample layer was lower because the thermal energy was expended on the phase change of the PCM (i.e., latent heat storage). It was confirmed that the catalyst-loaded MEPCM exhibited thermal control ability by slowing the rate of increase of the temperature of the 
catalyst layer. The heat absorption rate of the Ni/MEPCM was calculated by Eq. (3).

$$
W=\frac{Q_{0.2}}{\Delta t \times V}
$$

In this formula, $W\left(\mathrm{~W} \mathrm{~m}^{-3}\right)$ represents the heat absorption rate, $Q_{0.2}(\mathrm{~J})$ and $V\left(\mathrm{~m}^{3}\right)$ are the thermal storage capacity and volume, respectively, of $0.2 \mathrm{~g}$ of Ni/MEPCM, and $\Delta t$ (s) is the time during which the Ni/MEPCM stored heat. In this study, the loaded sample volume was approximately $59 \times 10^{-9} \mathrm{~m}^{3}$. The theoretical heat storage capacity of the loaded sample was approximately $171.7 \mathrm{~J}$, as determined by DSC. Therefore, $\mathrm{Q}_{0.2}$ was 34.3 J. Since the temperature difference between the two curves clearly occurred between 1 and $5 \mathrm{~min}$, the PCM completed the phase transformation in $4 \min (\Delta t=4 \mathrm{~s})$. Therefore, the catalyst-loaded MEPCM exhibited an average rate of heat absorption of nearly 2.4 MW $\mathrm{m}^{-3}$. In this calculation, the contribution of the sensible heat storage was neglected as the temperature difference between the two curves was insignificant. The resulting heat absorption rate is competitive with the heat exchange rate of some chemical heat storage materials and heat transfer technology that utilize $\mathrm{LHS}^{40-42}$. This promising result comes from the fact that the MEPCM is a high-density energy storage device, and the novel structure of direct catalyst loading onto the PCM reduces the heat transfer distance.

\section{Conclusion}


The use of MEPCM as a catalyst support was explored to control the local temperature rise of catalyst layers. MEPCM was fabricated from Al-Si microspheres. Ni was introduced as a catalyst for the $\mathrm{CO}_{2}$ methanation reaction by the impregnation method. The phase composition, morphology, and thermal storage capacity of the impregnated samples were evaluated. The catalyst performance of the Ni/MEPCM sample was investigated by estimating the $\mathrm{CO}_{2}$ conversion and $\mathrm{CH}_{4}$ selectivity when the $\mathrm{CO}_{2}$ methanation reaction was performed at $400{ }^{\circ} \mathrm{C}$. In addition, the thermal control characteristics of the MEPCM during an exothermic reaction were investigated. The primary results were as follows:

1) The phase composition, morphology, and heat storage capacity of the pure MEPCM did not change even after processing via the impregnation method. Nano-sized NiO particles were dispersed on the surface of the Ni/MEPCM. Therefore, the impregnation method, which is a conventional method for supporting catalysts, is applicable to MEPCM, and smooth scale-up can be expected for industrial applications.

2) The Ni/MEPCM exhibited appropriate performance as a catalyst support, with a significant increase in $\mathrm{CO}_{2}$ conversion and $\mathrm{CH}_{4}$ selectivity compared to those of $\alpha-\mathrm{Al}_{2} \mathrm{O}_{3}$ particles.

3) Because of the heat storage capacity of Ni/MEPCM, it absorbed the reaction heat at a 
favorable rate $\left(2.4 \mathrm{MW} \mathrm{m}^{-3}\right)$ and reduced the rate of increase of the catalyst layer temperature during the exothermic reaction. The risk of thermal runaway may be reduced by combining the material with existing cooling techniques and optimizing the feed gas conditions.

In conclusion, MEPCM can be used as an alternative catalyst support due to the excellent stability and activity of its ceramic shell. In the future, the optimization of MEPCM as a catalyst support using surface modification will be pursued to realize higher efficiency in material conversion to improve the economical aspect of the technique. 
1 Odunsi, A. O., O'Donovan, T. S. \& Reay, D. A. Dynamic Modeling of Fixed-Bed FischerTropsch Reactors with Phase Change Material Diluents. Chemical Engineering \& 
Technology 39, 2066-2076, doi:10.1002/ceat.201600196 (2016).

Zhang, M. et al. Encapsulated nano-heat-sinks for thermal management of heterogeneous chemical reactions. Nanoscale 2, doi:10.1039/c0nr00585a (2010).

Zhu, W. H. et al. A novel cooling structure with a matrix block of microfibrous media / phase change materials for heat transfer enhancement in high power $\mathrm{Li}$-ion battery packs. Journal of Cleaner Production 210, 542-551, doi:10.1016/j.jclepro.2018.11.043 (2019). Hasnain, S. M. Review on sustainable thermal energy storage technologies, part I: Heat storage materials and techniques. Energy Convers. Manage. 39, 1127-1138, doi:Doi 10.1016/S0196-8904(98)00025-9 (1998).

Farid, M. M., Khudhair, A. M., Razack, S. A. K. \& Al-Hallaj, S. A review on phase change energy storage: materials and applications. Energy Convers. Manage. 45, 1597-1615, doi:10.1016/j.enconman.2003.09.015 (2004).

Nomura, T., Okinaka, N. \& Akiyama, T. Technology of Latent Heat Storage for High Temperature Application: A Review. ISIJ Int. 50, 1229-1239, doi:DOI 10.2355/isijinternational.50.1229 (2010).

7 Sharma, A., Tyagi, V. V., Chen, C. R. \& Buddhi, D. Review on thermal energy storage with phase change materials and applications. Renewable and Sustainable Energy Reviews 13, 318-345, doi:10.1016/j.rser.2007.10.005 (2009).

8 Xie, B., Cheng, W.-I. \& Xu, Z.-m. Studies on the effect of shape-stabilized PCM filled aluminum honeycomb composite material on thermal control. Int. J. Heat Mass Transfer 91, 135-143, doi:10.1016/j.ijheatmasstransfer.2015.07.108 (2015).

9 Sevinchan, E., Dincer, I. \& Lang, H. A review on thermal management methods for robots. Appl. Therm. Eng. 140, 799-813, doi:10.1016/j.applthermaleng.2018.04.132 (2018).

10 Jankowski, N. R. \& McCluskey, F. P. A review of phase change materials for vehicle component thermal buffering. Applied Energy 113, 1525-1561, doi:10.1016/j.apenergy.2013.08.026 (2014).

11 Peng, G., Dou, G., Hu, Y., Sun, Y. \& Chen, Z. Phase Change Material (PCM) Microcapsules for Thermal Energy Storage. Adv. Polym. Tech. 2020, 1-20, doi:10.1155/2020/9490873 (2020).

12 Kenisarin, M. M. High-temperature phase change materials for thermal energy storage. Renewable and Sustainable Energy Reviews 14, 955-970, doi:10.1016/j.rser.2009.11.011 (2010).

13 Mohamed, S. A. et al. A review on current status and challenges of inorganic phase change materials for thermal energy storage systems. Renewable and Sustainable Energy Reviews 70, 1072-1089, doi:10.1016/j.rser.2016.12.012 (2017).

14 Blanco-Rodríguez, P., Rodríguez-Aseguinolaza, J., Risueño, E. \& Tello, M. Thermophysical 
characterization of $\mathrm{Mg}-51 \% \mathrm{Zn}$ eutectic metal alloy: A phase change material for thermal energy storage in direct steam generation applications. Energy 72, 414-420, doi:10.1016/j.energy.2014.05.058 (2014).

15 Risueño, E. et al. Mg-Zn-Al Eutectic Alloys as Phase Change Material for Latent Heat Thermal Energy Storage. Energy Procedia 69, 1006-1013, doi:10.1016/j.egypro.2015.03.193 (2015).

16 Huang, X., Zhu, C., Lin, Y. \& Fang, G. Thermal properties and applications of microencapsulated PCM for thermal energy storage: A review. Appl. Therm. Eng. 147, 841 855, doi:10.1016/j.applthermaleng.2018.11.007 (2019).

17 Nomura, T., Zhu, C., Sheng, N., Saito, G. \& Akiyama, T. Microencapsulation of Metal-based Phase Change Material for High-temperature Thermal Energy Storage. Sci Rep-Uk 5, doi:doi.org/10.1038/srep09117 (2015).

18 Nomura, T. et al. Microencapsulated phase change materials with high heat capacity and high cyclic durability for high-temperature thermal energy storage and transportation. Applied Energy 188, 9-18, doi:10.1016/j.apenergy.2016.11.025 (2017).

19 Sheng, N. et al. Development of a microencapsulated Al-Si phase change material with high-temperature thermal stability and durability over 3000 cycles. Journal of Materials Chemistry A 6, 18143-18153, doi:10.1039/c8ta04708a (2018).

20 Desai, A. N., Gunjal, A. \& Singh, V. K. Numerical investigations of fin efficacy for phase change material (PCM) based thermal control module. Int. J. Heat Mass Transfer 147, doi:10.1016/j.jijheatmasstransfer.2019.118855 (2020).

21 Gokon, N., Nakamura, S., Hatamachi, T. \& Kodama, T. Steam reforming of methane using double-walled reformer tubes containing high-temperature thermal storage $\mathrm{Na2CO} / \mathrm{MgO}$ composites for solar fuel production. Energy 68, 773-782, doi:10.1016/j.energy.2014.01.107 (2014).

22 Pattison, R. C. \& Baldea, M. A thermal-flywheel approach to distributed temperature control in microchannel reactors. A/ChE J. 59, 2051-2061, doi:10.1002/aic.13991 (2013).

$23 \mathrm{Li}, \mathrm{K}$. et al. A yolk/shell strategy for designing hybrid phase change materials for heat management in catalytic reactions. Journal of Materials Chemistry A 5, 24232-24246, doi:10.1039/c7ta07147g (2017).

24 Aika, K. et al. Syntax of referencing in Catalytic Handbook [Translated from Japanese.]. (ed. Catalysis society of Japan) 319-338 (Kodansha Ltd., 2008).

25 Tsuboi, Y., Takafuji, M., Ohara, H., Shinomiya, H., Takano, H., Izumiya, K. SNG Production from Woody Biomass Using Gasification Process. Journal of the Combustion Society of Japan 58, 137-144, doi:DOI 10.20619/jcombsj.58.185_137 (2016).

26 Rönsch, S. et al. Review on methanation - From fundamentals to current projects. Fuel 
166, 276-296, doi:10.1016/j.fuel.2015.10.111 (2016).

27 Falbo, L. et al. Kinetics of $\mathrm{CO} 2$ methanation on a Ru-based catalyst at process conditions relevant for Power-to-Gas applications. Applied Catalysis B: Environmenta/225, 354-363, doi:10.1016/j.apcatb.2017.11.066 (2018).

Frontera, P., Macario, A., Ferraro, M. \& Antonucci, P. Supported Catalysts for CO2 Methanation: A Review. Catalysts 7, doi:10.3390/catal7020059 (2017).

29 Meylan, F. D., Piguet, F.-P. \& Erkman, S. Power-to-gas through CO2 methanation: Assessment of the carbon balance regarding EU directives. Journal of Energy Storage 11, 16-24, doi:10.1016/j.est.2016.12.005 (2017).

30 Götz, M. et al. Renewable Power-to-Gas: A technological and economic review. Renewable Energy 85, 1371-1390, doi:10.1016/j.renene.2015.07.066 (2016).

31 Rahmani, S., Rezaei, M. \& Meshkani, F. Preparation of highly active nickel catalysts supported on mesoporous nanocrystalline $\mathrm{\gamma}-\mathrm{Al} 2 \mathrm{O} 3$ for $\mathrm{CO} 2$ methanation. Journal of Industrial and Engineering Chemistry20, 1346-1352, doi:10.1016/j.jiec.2013.07.017 (2014).

32 Lefebvre, J., Bajohr, S. \& Kolb, T. Modeling of the transient behavior of a slurry bubble column reactor for $\mathrm{CO} 2$ methanation, and comparison with a tube bundle reactor. Renewable Energy 151, 118-136, doi:10.1016/j.renene.2019.11.008 (2020).

33 Try, R., Bengaouer, A., Baurens, P. \& Jallut, C. Dynamic modeling and simulations of the behavior of a fixed-bed reactor-exchanger used for $\mathrm{CO} 2$ methanation. A/ChE J. 64, 468480, doi:10.1002/aic.15874 (2018).

34 Frey, M., Romero, T., Roger, A.-C. \& Edouard, D. An intensification of the CO2 methanation reaction: Effect of carbon nanofiber network on the hydrodynamic, thermal and catalytic properties of reactors filled with open cell foams. Chem. Eng. Sci. 195, 271-280, doi:10.1016/j.ces.2018.11.028 (2019).

35 Sakamoto, K. Alumina Hydrate and Alumina [Translated from Japanese.]. Journal of the japan institute of light metals 22, 295-308 (1972).

36 Garbarino, G., Riani, P., Magistri, L. \& Busca, G. A study of the methanation of carbon dioxide on Ni/Al2O3 catalysts at atmospheric pressure. Int. J. Hydrogen Energy 39, 1155711565, doi:10.1016/j.ijhydene.2014.05.111 (2014).

37 Chein, R.-Y. \& Wang, C.-C. Experimental Study on CO2 Methanation over Ni/Al2O3, Ru/Al2O3, and Ru-Ni/Al2O3 Catalysts. Catalysts 10, doi:10.3390/catal10101112 (2020).

38 Stangeland, K., Kalai, D., Li, H. \& Yu, Z. CO 2 Methanation: The Effect of Catalysts and Reaction Conditions. Energy Procedia 105, 2022-2027, doi:10.1016/j.egypro.2017.03.577 (2017).

39 Fujita, S. Mechanism of hydrogenation of carbon dioxide over metal catalysts [Translated from Japanese.]. Doctoral dissertation in Hokkaido University, doi:10.11501/3083386 
(1995).

40 Iwai, Y. Syntax of referencing in Technology for practical application of heat storage systems and materials [Translated from Japanese.]. 137-145 (S \& T publisher, 2018).

41 Zamengo, M., Ryu, J. \& Kato, Y. Chemical Heat Storage of Thermal Energy from a Nuclear Reactor by Using a Magnesium Hydroxide/Expanded Graphite Composite Material. Energy Procedia 71, 293-305, doi:10.1016/j.egypro.2014.11.882 (2015).

42 Shkatulov, A., Takasu, H., Kato, Y. \& Aristov, Y. Thermochemical energy storage by LiNO3doped $\mathrm{Mg}(\mathrm{OH}) 2$ : Rehydration study. Journal of Energy Storage 22, 302-310, doi:10.1016/j.est.2019.01.014 (2019).

\section{Acknowledgements}

The authors greatly appreciate the financial support from the JSPS KAKENHI Grant Number 19K22224, 26 ${ }^{\text {th }}$ The thermal \& Electric Energy Technology Inc. Foundation, and Steel Foundation for Environmental Protection Technology, Japan. A part of this work was conducted at Hokkaido University, supported by "Nanotechnology Platform" Program of the Ministry of Education, Culture, Sports, Science and Technology (MEXT), Japan.

\section{Author contributions}

T. T. conducted experiments, and wrote the manuscript. H. K., S. H., D. A., K. A., and Y. K., helped with experimental work and data analysis, reviewed and commented on the manuscript. T. N. conceived the idea, wrote the manuscript, and supervised the project. 


\section{Additional information}

Competing financial interests: The authors declare no competing financial interests. 


\section{Figures}

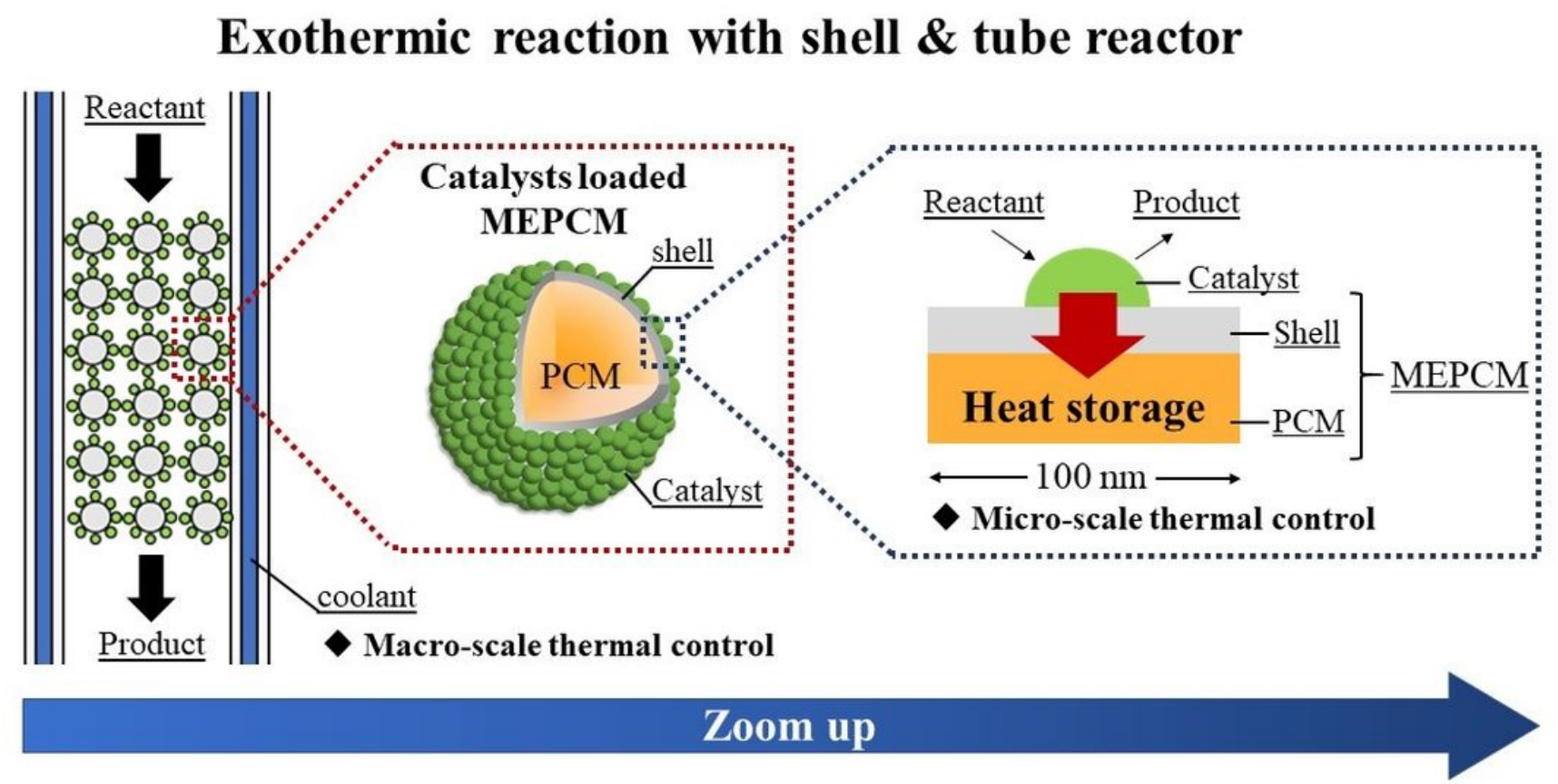

Figure 1

Schematic diagram of the catalyst-loaded MEPCM and the thermal control system. 


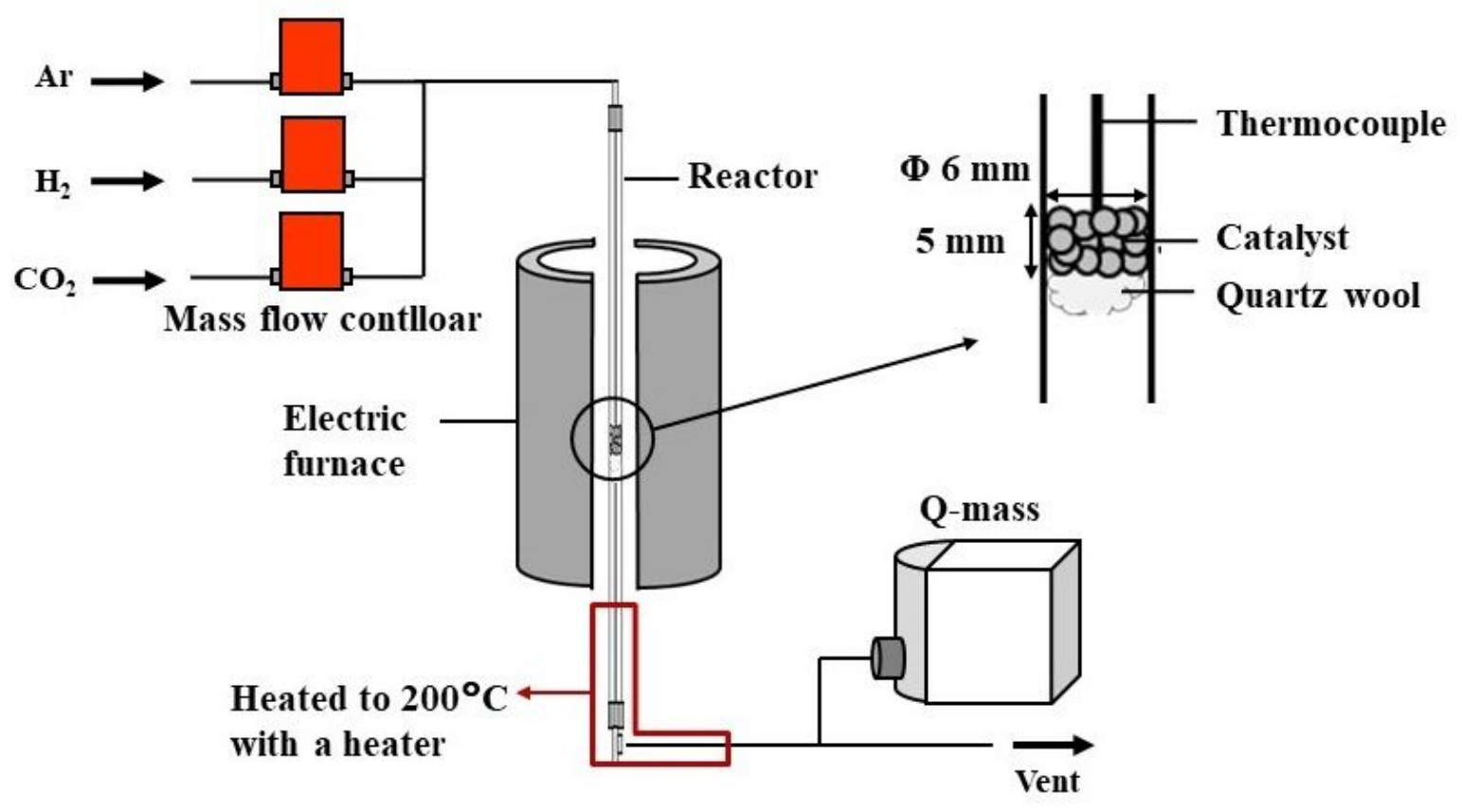

Figure 2

Schematic diagram of the vertical fixed bed tubular reactor.

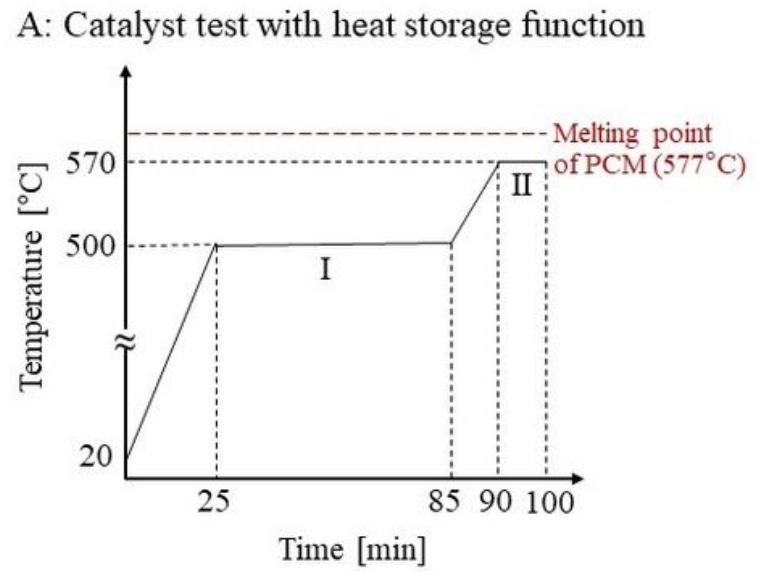

B: Catalyst test without heat storage function

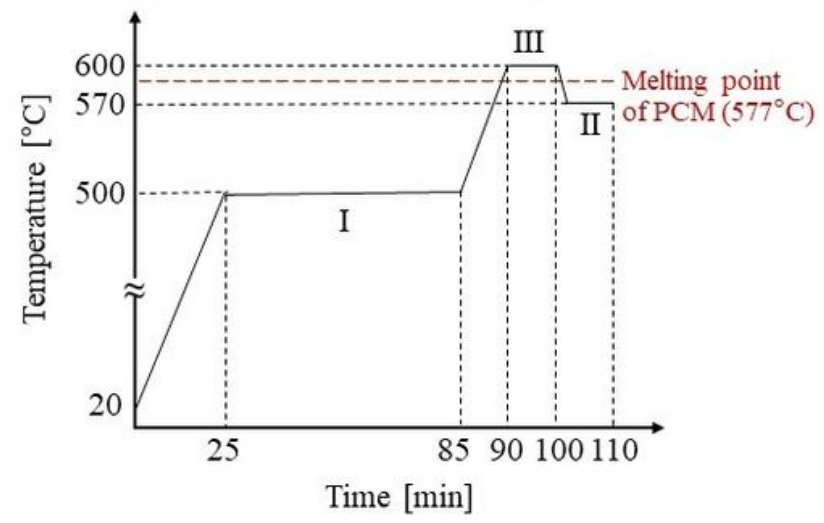

\section{Figure 3}

Temperature program of the two different reaction conditions. In the condition A, internal PCM is solid when reaction starts. In the condition B, internal PCM is liquid when reaction starts. Stage $\mathbb{~ : ~} \mathrm{H} 2$ and $\mathrm{Ar}$

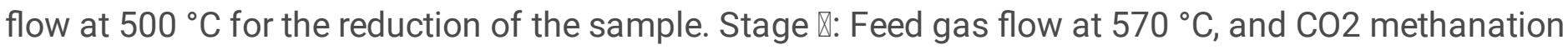




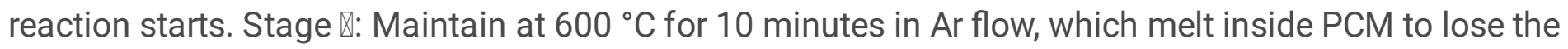
heat storage capacity of the sample.

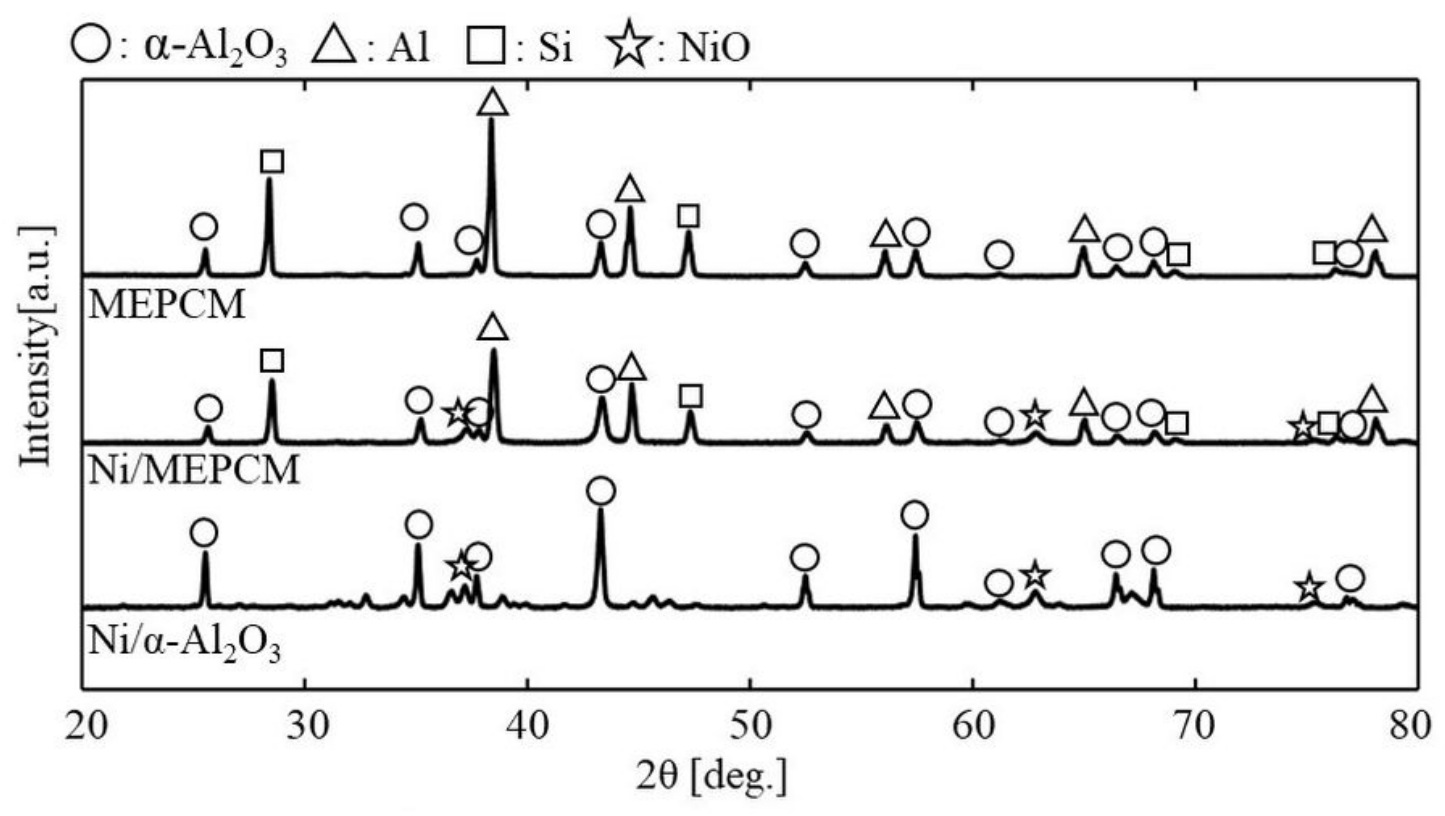

Figure 4

X-ray diffraction (XRD) patterns of the MEPCM, Ni/MEPCM, and Ni/a-Al2O3. 


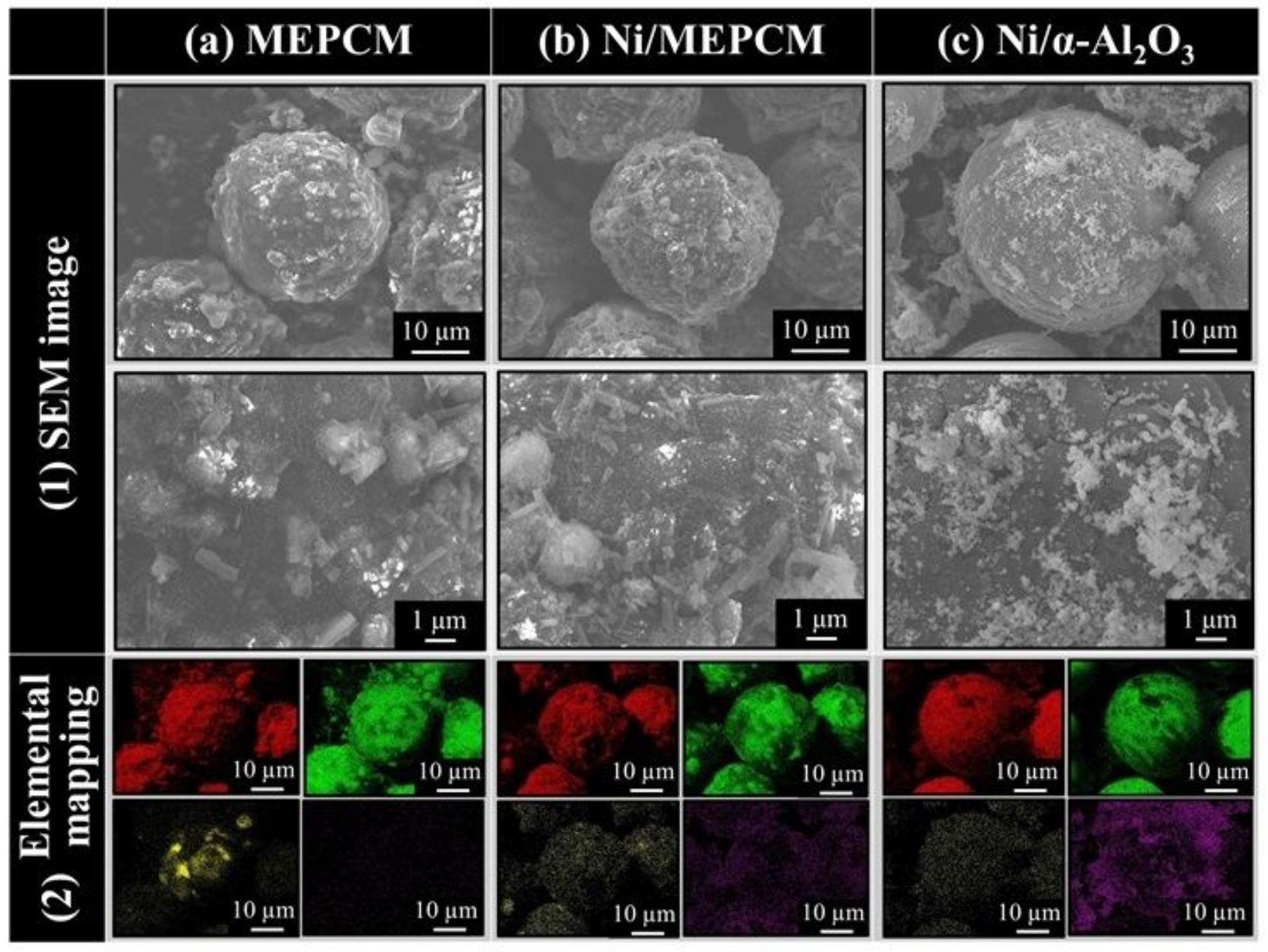

Figure 5

Scanning electron microscopy (SEM) image and the Energy dispersive spectroscopy (EDS) elemental mapping of the (a) MEPCM, (b) Ni/MEPCM, and (c) Ni/a-Al203.. In the elemental mapping, the red area represents $\mathrm{O}$, the green area represents $\mathrm{Al}$, the yellow area represents $\mathrm{Si}$ and the purple area represents $\mathrm{Ni}$. 


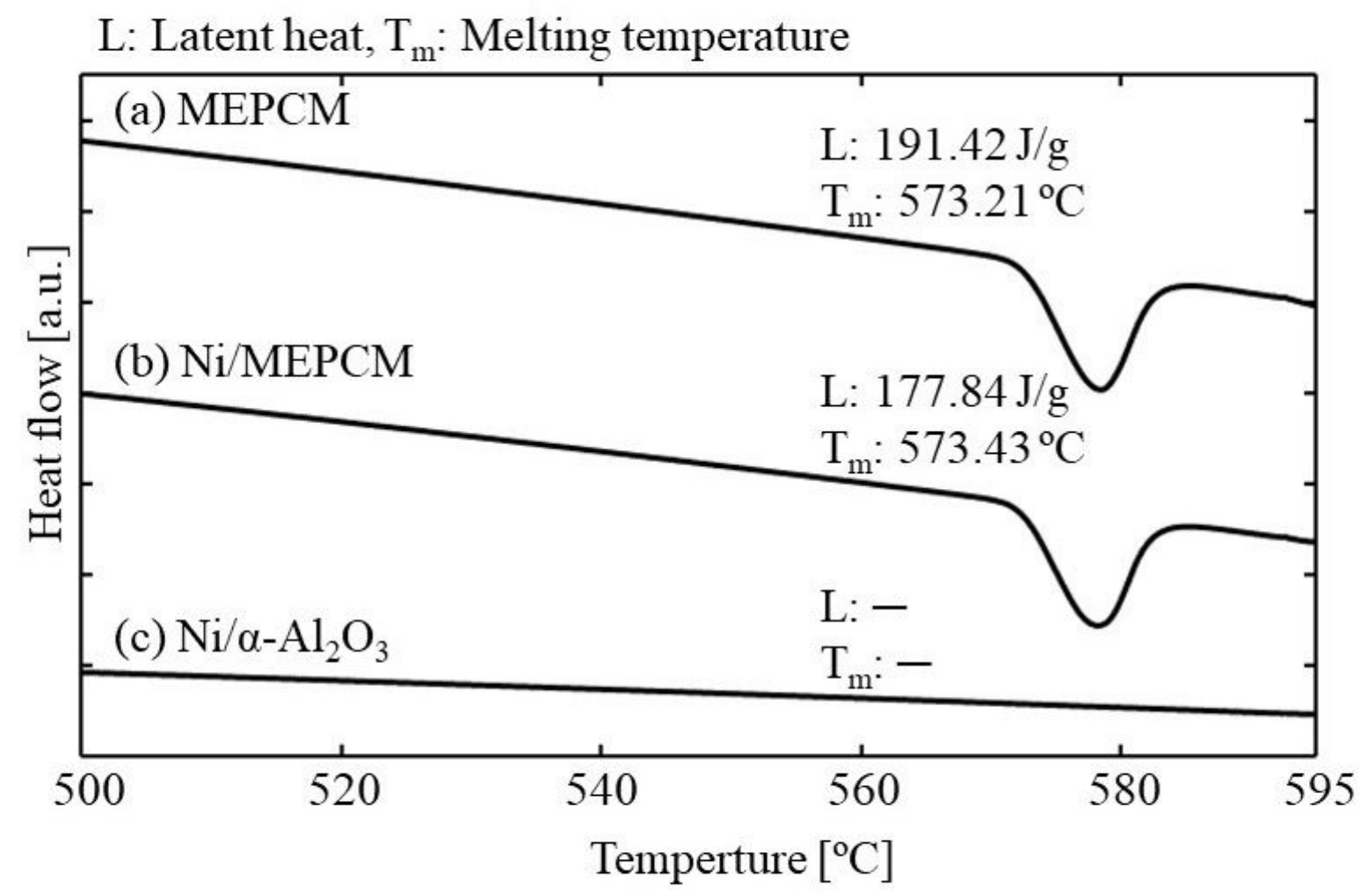

Figure 6

Heating DSC curves of the MEPCM, Ni/MEPCM, and Ni/ a-Al2O3. 


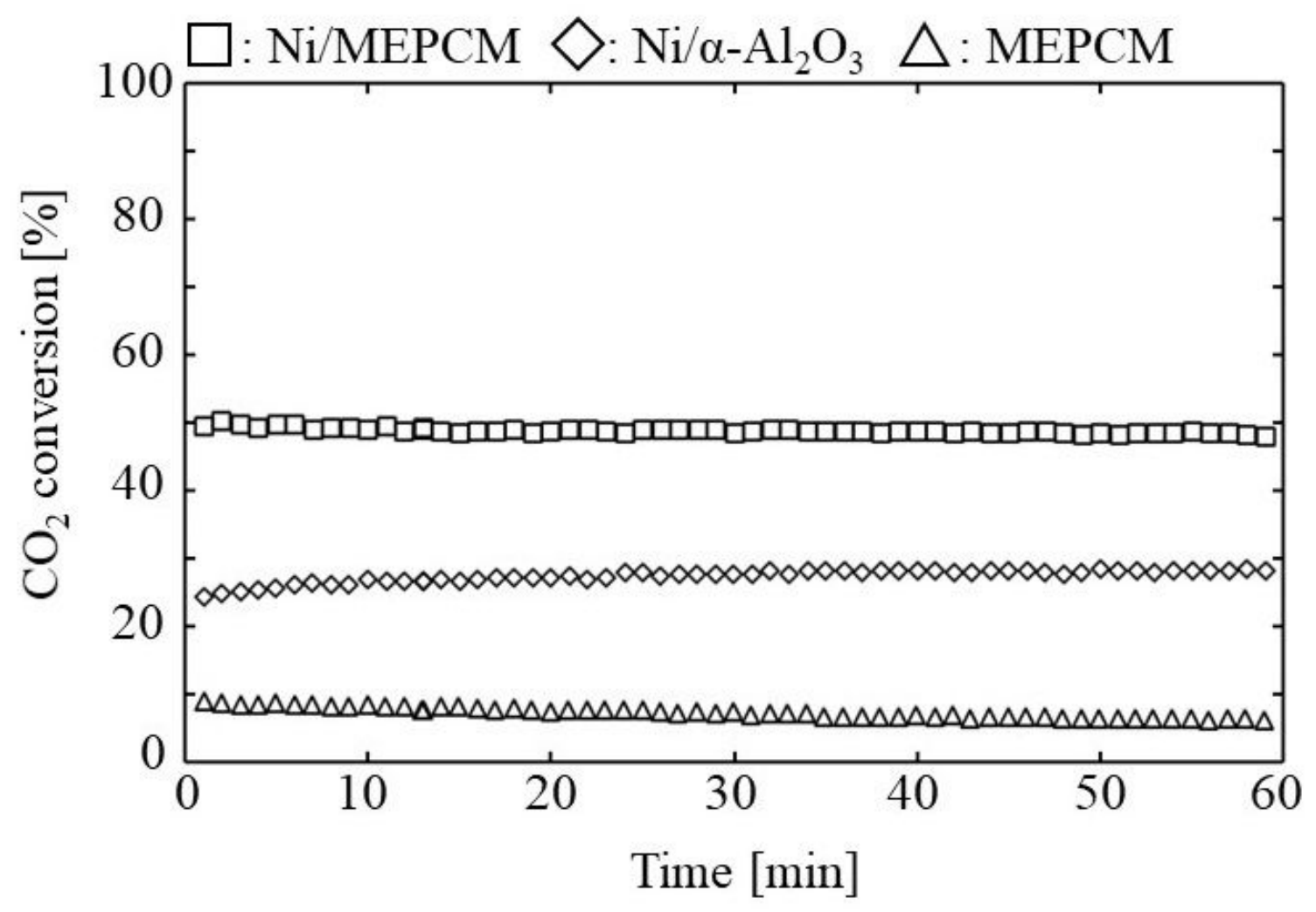

Figure 7

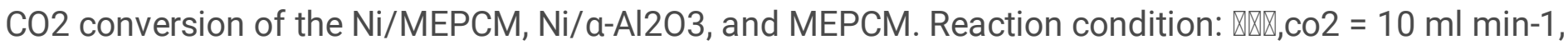

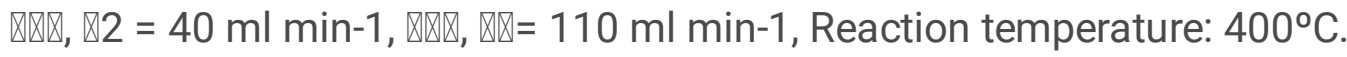




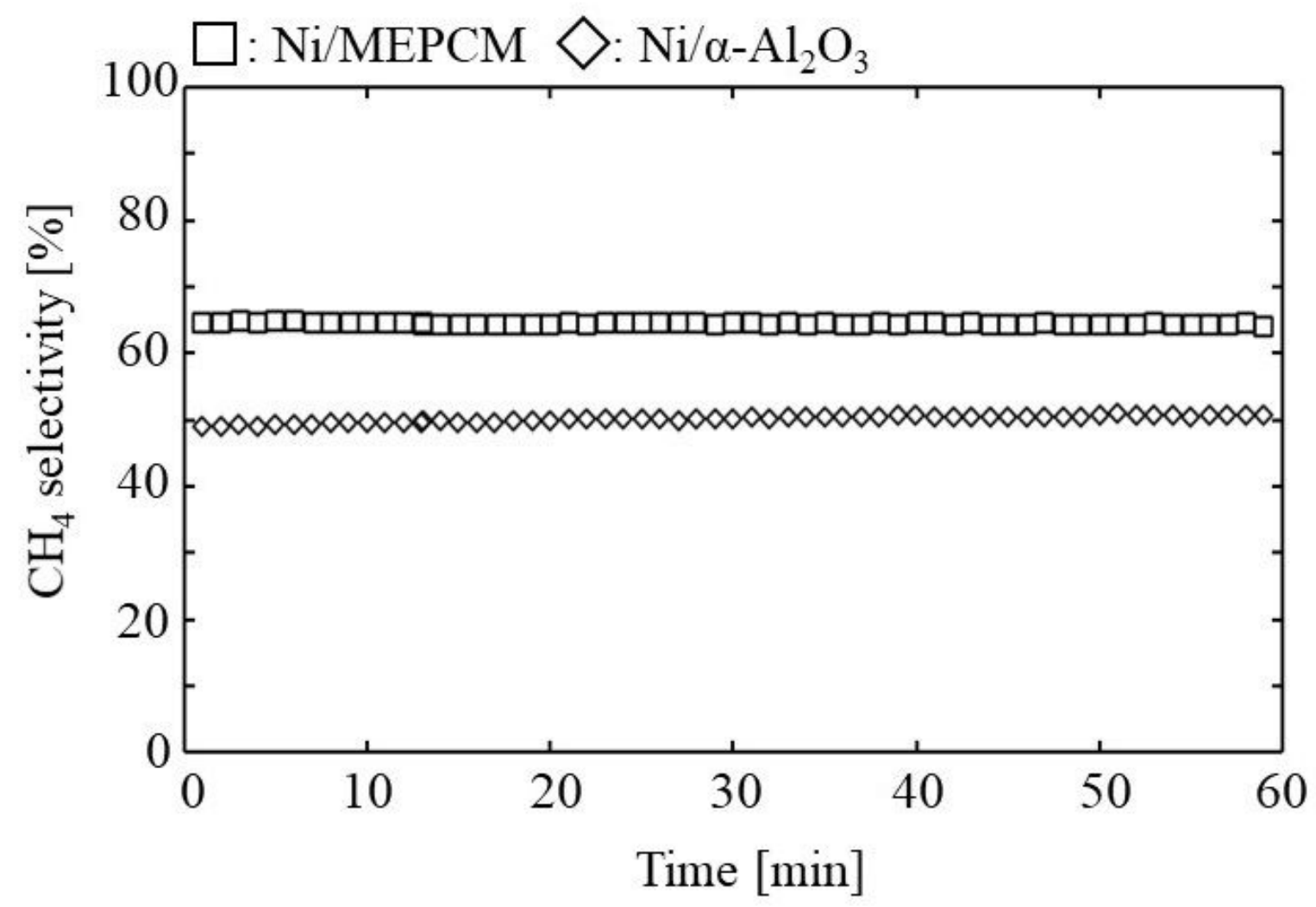

Figure 8

$\mathrm{CH} 4$ selectivity of the Ni/MEPCM, Ni/a-Al2O3, and MEPCM. Reaction condition: $\mathbb{Q}$ Q

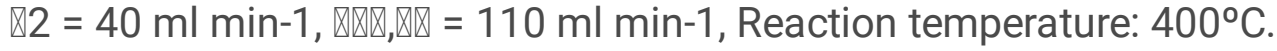




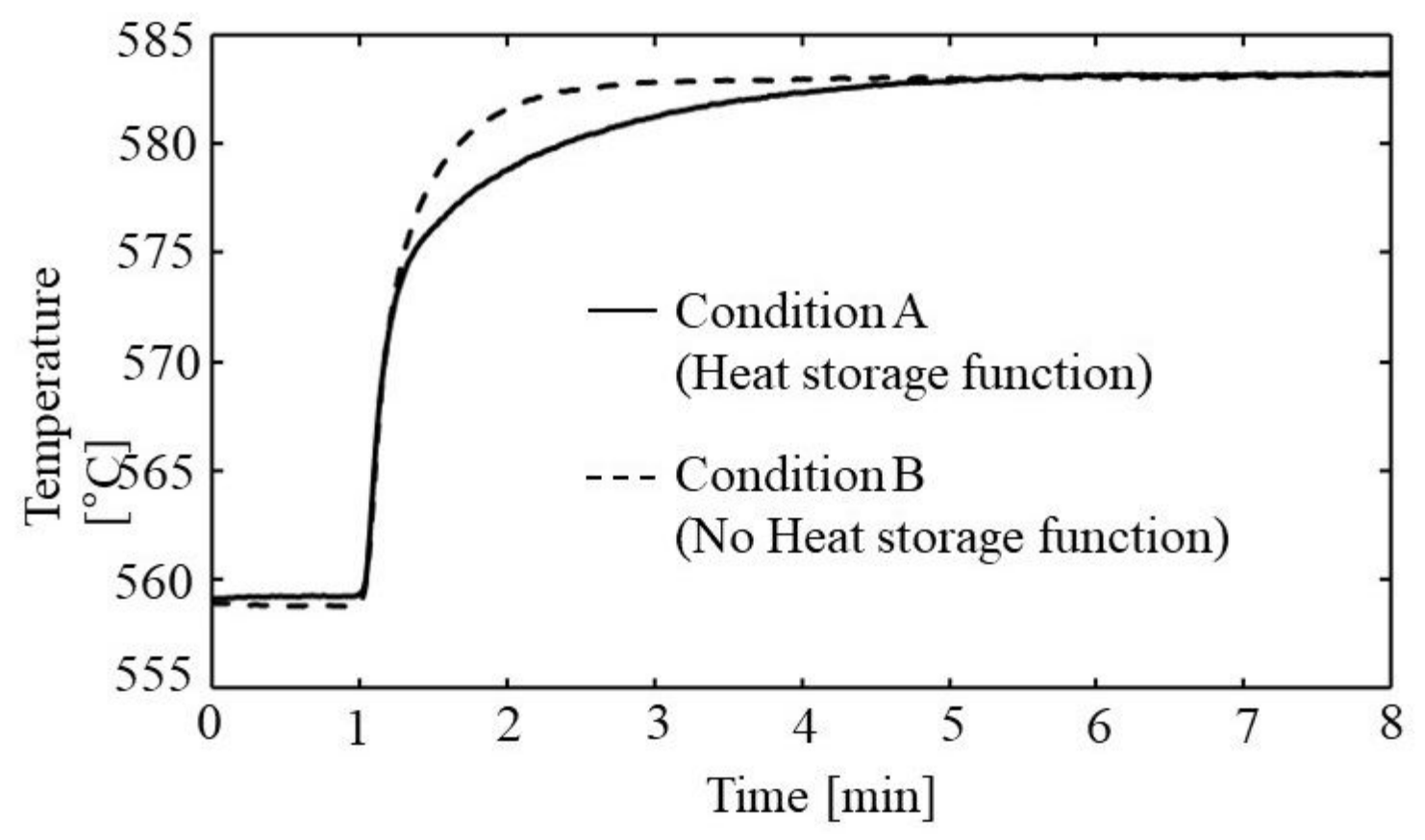

Figure 9

The temperature change of the Ni/MEPCM layer during $\mathrm{CO} 2$ methanation. Feed gas was introduced at 1 min after the starts of measurement. In the condition A, the MEPCM has heat storage capacity. In the

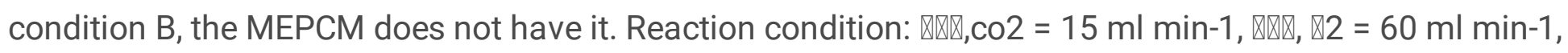

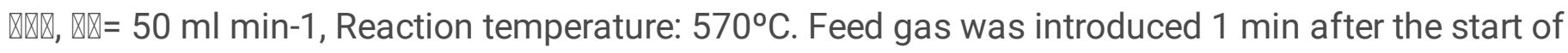
measurement. 